\title{
Outubro Rosa: uma Abordagem Humanizada de Promoção e Prevenção de Agravos a Saúde da Mulher
}

\author{
Santos, Jose Paulo dos Anjos; Correia, Malena de Carvalho; Ferreira, Fabricio \\ Nicacio; Dantas, Diego da Silva; Santos, Jose Ronaldo Alves dos \\ Universidade Federal de Sergipe — jp_anjos1@hotmail.com
}

Introdução: a Política Nacional de Atenção Integral a Saúde da Mulher (PNAISM) foi criada em 2004 e é fundamentada nos princípios do SUS: integralidade, universalidade e equidade da assistência à saúde. a partir desses princípios a PNAISM busca efetivar ações de promoção, prevenção e recuperação da saúde, com enfoque aos direitos sexuais e reprodutivos, de portadoras de doenças crônicas não transmissíveis, além de atuar no combate a violência sexual e doméstica e no tratamento de mulheres acometidas pelo vírus HIV/Aids. Seu principal objetivo está voltado à implementação de ações de saúde, que garantam os direitos humanos da mulher e reduzam a morbimortalidade por causas previníveis e evitáveis. Objetivo: Relatar a experiência dos acadêmicos de enfermagem, atuando em uma das Unidades Básicas de Saúde do município de Lagarto/Sergipe em comemoração ao outubro rosa. Métodos: Estudo Observacional com abordagem educativa em que os acadêmicos de enfermagem, além de observarem a dinâmica de trabalho realizado pelos profissionais de saúde neste mês dedicado as mulheres. Colaboraram nas atividades práticas de autoexame das mamas, teste de glicemia, bem como na realização de apresentações teatrais com foco na prevenção do câncer de mama e colo de útero. Resultados: Pensou-se inicialmente em uma maneira simples e dinâmica de mostrar a importância da prevençãodo câncer de colo do útero e de mama. para isso, os alunos apresentaram um slide com informações acerca de sinais e sintomas do câncer do colo do útero e das mamas e como prevenir tais doenças. Após, realizaram uma peça teatral a qual utilizou-se linguagem de fácil compreensão e destacou-se o assunto anteriormente abordado. Houve após a peça um momento para sanar dúvidas a respeito do assunto em questão, percebeu-se que algumas mulheres se sentiram um pouco desconfortável em realizar perguntas, enquanto outras realizaram várias perguntas a respeito do tema. Neste dia ofereceu-se os serviços: autoexame das mamas; preventivo do câncer do colo de útero, bem como a oferta de camisinhas além de orientações quanto ao planejamento familiar, teste de glicemia, aferição da pressão arterial e atendimento médico exclusivo para usuárias. Verificou-se a preocupação da população feminina quanto a sua saúde, visto que aproximadamente 150 mulheres compareçam a unidade básica durante esse dia. Conclusão: a saúde da mulher não está voltada somente a saúde reprodutiva, pois ela deve ser vista de forma integral, porém observase que muitas mulheres ainda carregam esse pensamento, deixando de cuidar de agravos previníveis, como: diabete, hipertensão e até mesmo o câncer do colo de útero e de mama. Percebese ainda, a relevância desses eventos para o desenvolvimento de atividades de promoção e prevenção a saúde da mulher. Desse modo,essas atividades são ferramentas simples que podem ser utilizada em outros meses do ano, visto que o cuidado a saúde deve ser integral e contínuo.

Santos, Jose Paulo dos Anjos; Correia, Malena de Carvalho; Ferreira, Fabricio Nicacio; Dantas, Diego da Silva; Santos, Jose Ronaldo Alves dos. Outubro Rosa: uma Abordagem Humanizada de Promoção e Prevenção de Agravos a Saúde da Mulher. In: Anais do Congresso Internacional de Humanidades \& Humanização em Saúde [= Blucher Medical Proceedings, num.2, vol.1]. São Paulo: Editora Blucher, 2014. ISSN 2357-7282

DOI 10.5151/medpro-cihhs-10357 